\title{
Reactive Retinal Astrocytic Tumor (Focal Nodular Gliosis): A Case Report
}

\author{
Lauren E. Hudson ${ }^{a}$ Pia R. Mendoza ${ }^{a, b}, c$ Jiong Yan ${ }^{a}$ Hans E. Grossniklaus ${ }^{a, b}, c$

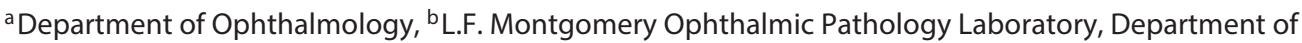 \\ Ophthalmology, BT 428 Emory Eye Center, and ' Department of Pathology and Laboratory Medicine, \\ Emory University School of Medicine, Atlanta, Ga., USA
}

\section{Key Words}

Reactive retinal astrocytic tumor - Massive retinal gliosis .

Vasoproliferative tumor · Focal nodular gliosis · Proliferative vitreoretinopathy

\section{Abstract \\ Purpose: To report the clinical and histopathological find- ings of a reactive retinal astrocytic tumor (RRAT) that pro- gressed to massive retinal gliosis. Observations: The patient presented with an elevated, white-yellow retinal mass and extensive retinal exudation in the left eye. Progressive en- largement of the mass and proliferative vitreoretinopathy eventually led to phthisis bulbi and enucleation. Histologi- cally, the mass showed a predominant astrocytic compo- nent with intense glial fibrillary acidic protein staining, hy- perplasia, fibrous metaplasia, and osseous metaplasia of the retinal pigment epithelium. The Ki-67 proliferative index was $<5 \%$, and few scattered vascular channels were observed. Conclusions and Importance: These findings show that this tumor is the result of a reactive glial process rather than of neoplastic vascular proliferation. Massive retinal gliosis probably represents the advanced stage of RRAT.}

(c) 2016 S. Karger AG, Basel

\section{KARGER}

๑) 2016 S. Karger AG, Basel

E-Mail karger@karger.com

www.karger.com/oop

\section{Introduction}

Reactive retinal astrocytic tumor (RRAT) is a reactive pseudoneoplastic proliferation of glial cells with a vascular component arising secondary to retinal disease or trauma. A recent analysis identifying common histopathological and immunohistochemical features of these tumors suggested new diagnostic categories based on size that encompass tumors previously termed retinal vasoproliferative tumors and massive retinal glioses [1]. Although there has been some controversy regarding the degree to which vascular or glial cells drive the pathology of these lesions [2,3], numerous recent histopathological analyses have identified glial astrocytes as the predominant component even of early tumors [1,3-5]. The present case illustrates tumor progression from a focal nodular gliosis obstructing $<25 \%$ of the vitreous to a massive retinal gliosis, with histological features that further support this disease as a reactive astrocytic process with a minor vascular component. 


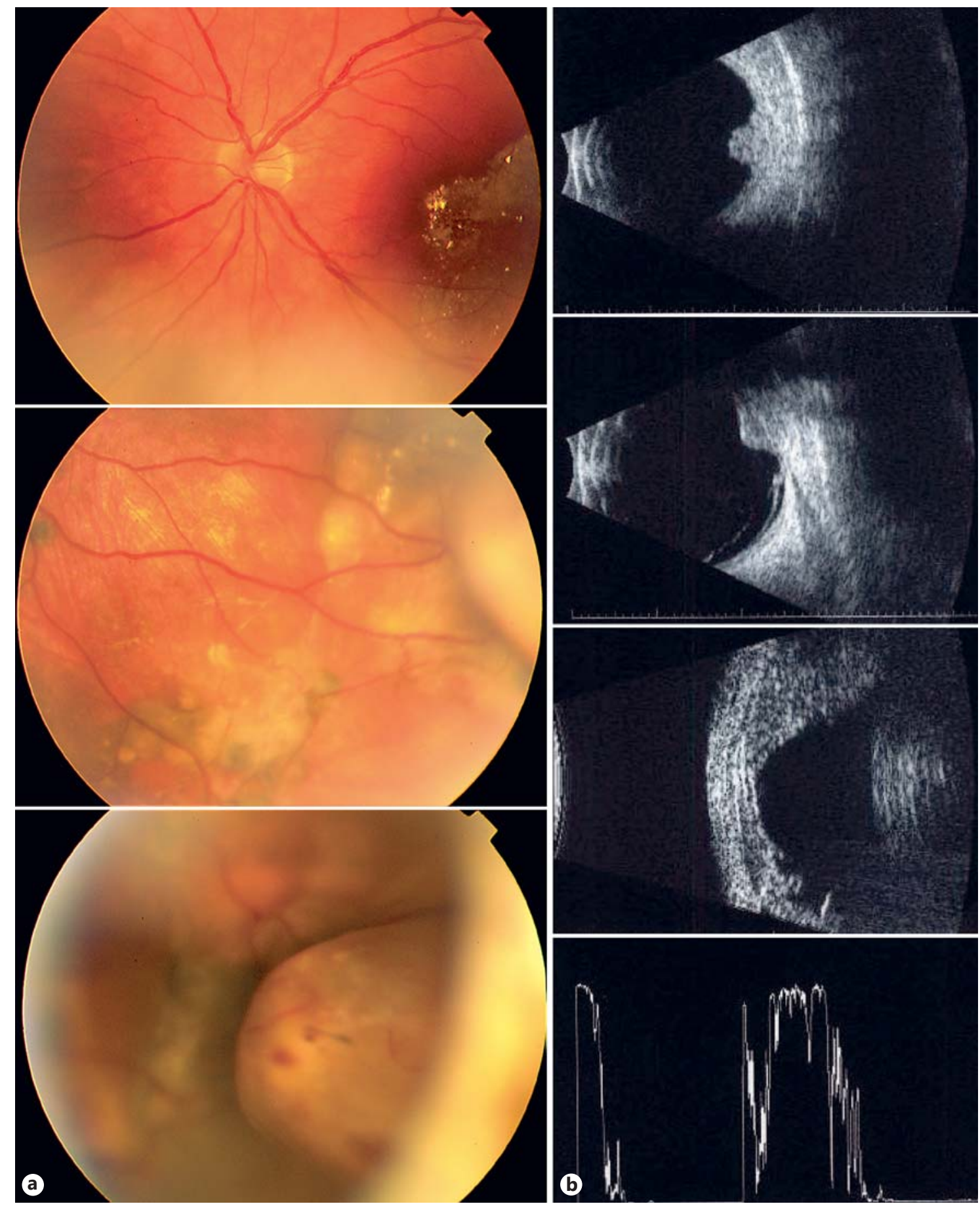

Fig. 1. a Initial funduscopic images showed an elevated inferotemporal white-yellow mass anterior to the equator with retinal pigment epithelium changes, shallow retinal detachment, and extensive retinal exudates from the temporal periphery extending to the macular area. b Ultrasound showed a solid lesion with medium irregular internal reflectivity centered at 3:30 equator measuring $3.8 \mathrm{~mm}$ (height) $\times 6.3 \times 7.0 \mathrm{~mm}$ (base). 

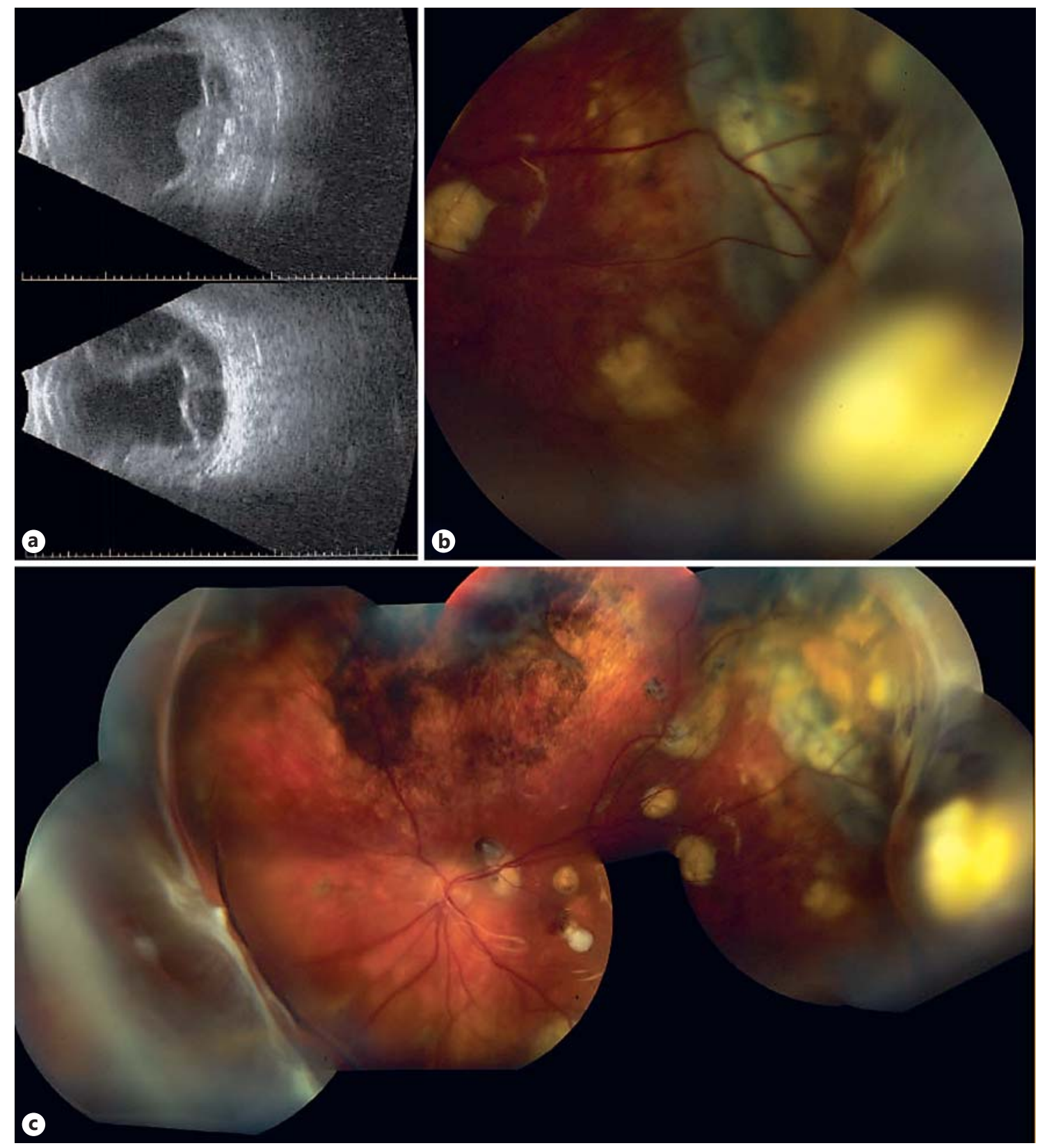

Fig. 2. a Ultrasound showed an increase in lesion size to 4.2 (height) $\times 10.1 \times 11.5 \mathrm{~mm}$ (base), increased subretinal fluid around the lesion, and peripheral scleral buckling effect. b, c Images post pars plana vitrectomy, scleral buckle, and silicone oil showed an active-looking lesion with subretinal fibrosis and extensive retinal pigment epithelium changes.

\section{Case Report}

An 18-year-old female presented with blurred vision in the left eye of several weeks' duration. Ocular history included blunt facial trauma 3 weeks prior to consultation and trauma to the left eye causing lid ecchymosis 1 year prior. Best corrected visual acuity was $20 / 25^{-2}$ in the right eye and $20 / 100$ in the left eye with a left nasal visual field defect. Anterior segment examination of both eyes and fundus examination of the right eye were normal. Examination of the left eye revealed an elevated, white-yellow mass in the inferotemporal retina anterior to the equator, with associated massive retinal exudation in the temporal periphery extending to the macular area as well as a shallow serous retinal detachment (fig. 1). B scan ultrasonography showed an elevated, solid lesion with medium internal reflectivity measuring $3.8 \mathrm{~mm}$ (height) $\times 6.3 \times 7.0 \mathrm{~mm}$ (base). Systemic workup for von Hippel- 

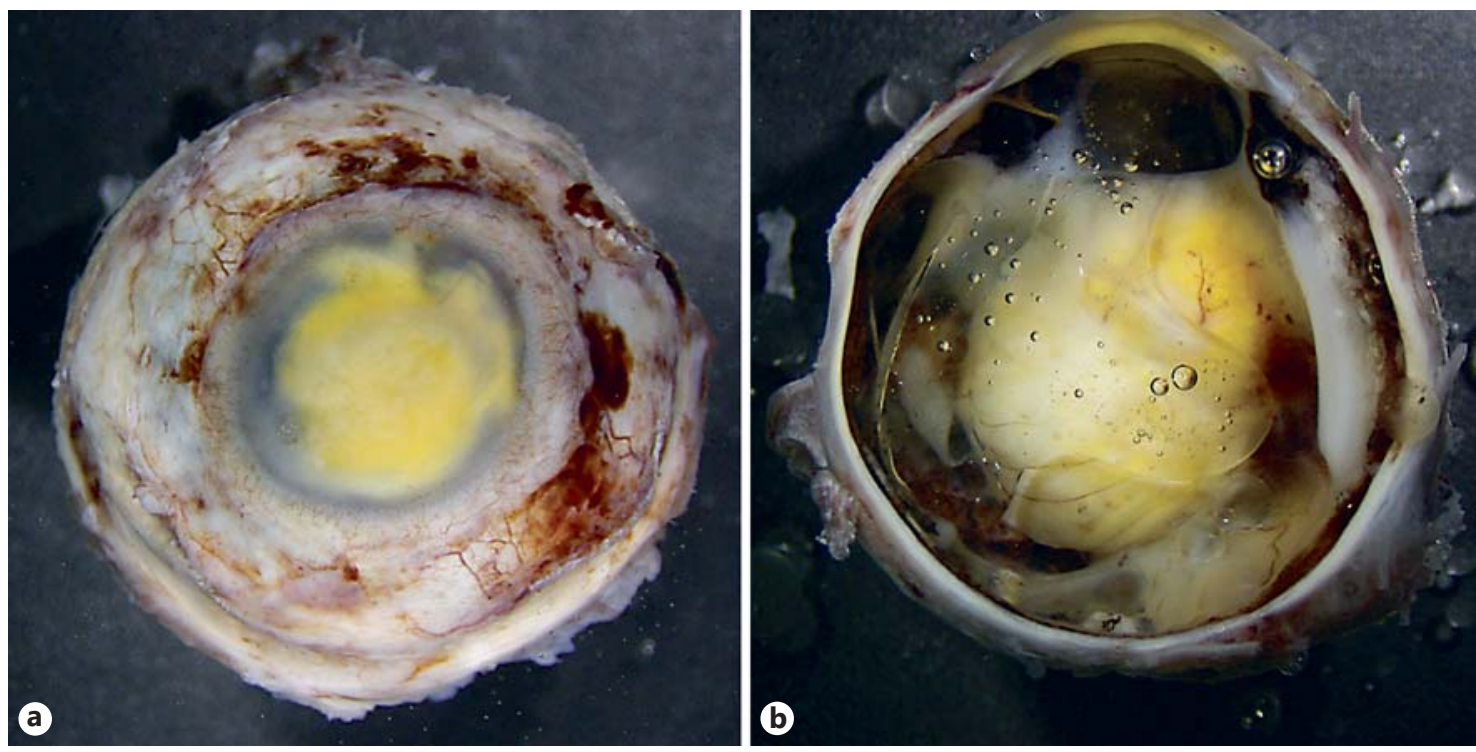

Fig. 3. a A whitish central corneal opacity and yellow material in the anterior chamber were present. b The gross tumor located inferotemporally measured $15 \times 10 \mathrm{~mm}$. Retinal detachment and vitreous with silicone oil were also observed.

Lindau disease was normal. The patient was diagnosed with a retinal angioma of the left eye.

Treatment was deferred until the patient, who was 5 months pregnant at the time of the initial consultation, had given birth. Progressive retinal exudation was observed during the interim phase. The mass decreased in size following photodynamic therapy, and the exudative retinal detachment resolved. Three months later, however, vision in the patient's left eye had declined to counting fingers. She was found to have proliferative vitreoretinopathy with traction retinal detachment of the macula. The patient underwent pars plana vitrectomy with membrane peeling and a second round of photodynamic therapy. In the following 6 years, the patient had recurrent serous and traction retinal detachments with proliferative vitreoretinopathy and underwent three retinal surgeries with silicone oil, scleral buckling, and endolaser ablation of the mass. Still, the mass increased in size to $4.2 \times 10.1 \times 11.5 \mathrm{~mm}$ (fig. 2). Eventually the eye became phthisical and was enucleated.

The enucleated globe measured $22 \times 22 \times 21 \mathrm{~mm}$ (fig. 3). The cornea, measuring $11 \times 10 \mathrm{~mm}$, showed a whitish central opacity and corneal scarring with band keratopathy. The anterior chamber contained a proteinaceous material, and there was neovascularization of the iris with associated peripheral anterior synechiae. The optic nerve displayed pseudo Schnabel's cavernous degeneration. The retina was detached and disorganized, with a lobulated whiteyellow $15 \times 10 \mathrm{~mm}$ mass located inferotemporally. Microscopic examination of the mass revealed calcifications and numerous spindle-shaped cells with bland nuclei and filamentous eosinophilic cytoplasm (fig. $4 \mathrm{a}-\mathrm{d}$ ). There were scattered vascular channels with hyalinized walls within the mass and collagenized fibrovascular tissue under the mass. Hyperplasia, fibrous metaplasia, and osseous metaplasia of the retinal pigment epithelium were also noted. The Ki-67 proliferative index was $<5 \%$ (fig. 4 e), and cells stained positive for glial fibrillary acidic protein (GFAP) (fig. 4f).

\section{Discussion and Conclusions}

Based on clinical and histopathological findings, the patient was diagnosed with massive retinal gliosis, a benign retinal glial proliferation. A recent review of numerous retinal glioses found this condition to be a spectrum of diseases that could be divided into three categories based on size and which encompassed tumors referred to either as RRAT [4] or previously as retinal vasoproliferative tumors [6]. These lesions are commonly unilateral and solitary but can also be bilateral, multiple, or diffuse [6]. They are nonfamilial, have no gender predilection, and typically develop in patients around 40 years of age. In early stages these tumors present as yellow-red retinal masses usually located in the inferotemporal pre-equatorial area $[1,6]$. These are usually accompanied by massive exudation with or without retinal detachment and may also appear vascular or hyperfluorescent on fluorescein angiography. In later disease stages, including the present case at enucleation, lesions occupy $>50 \%$ of the vitreous and destroy $90-100 \%$ of the retina.

This disease entity has previously been described with numerous terms, each emphasizing either its glial or vascular components. 'Peripheral retinal angiomas' were first described in 1966 by Henkind and Morgan as having a 'Coats'-like appearance' [7, 8]. Diagnoses including 'angioma-like mass' in retinopathy of prematurity [9], 'retinal angiomatous mass' after retinal detachment surgery 

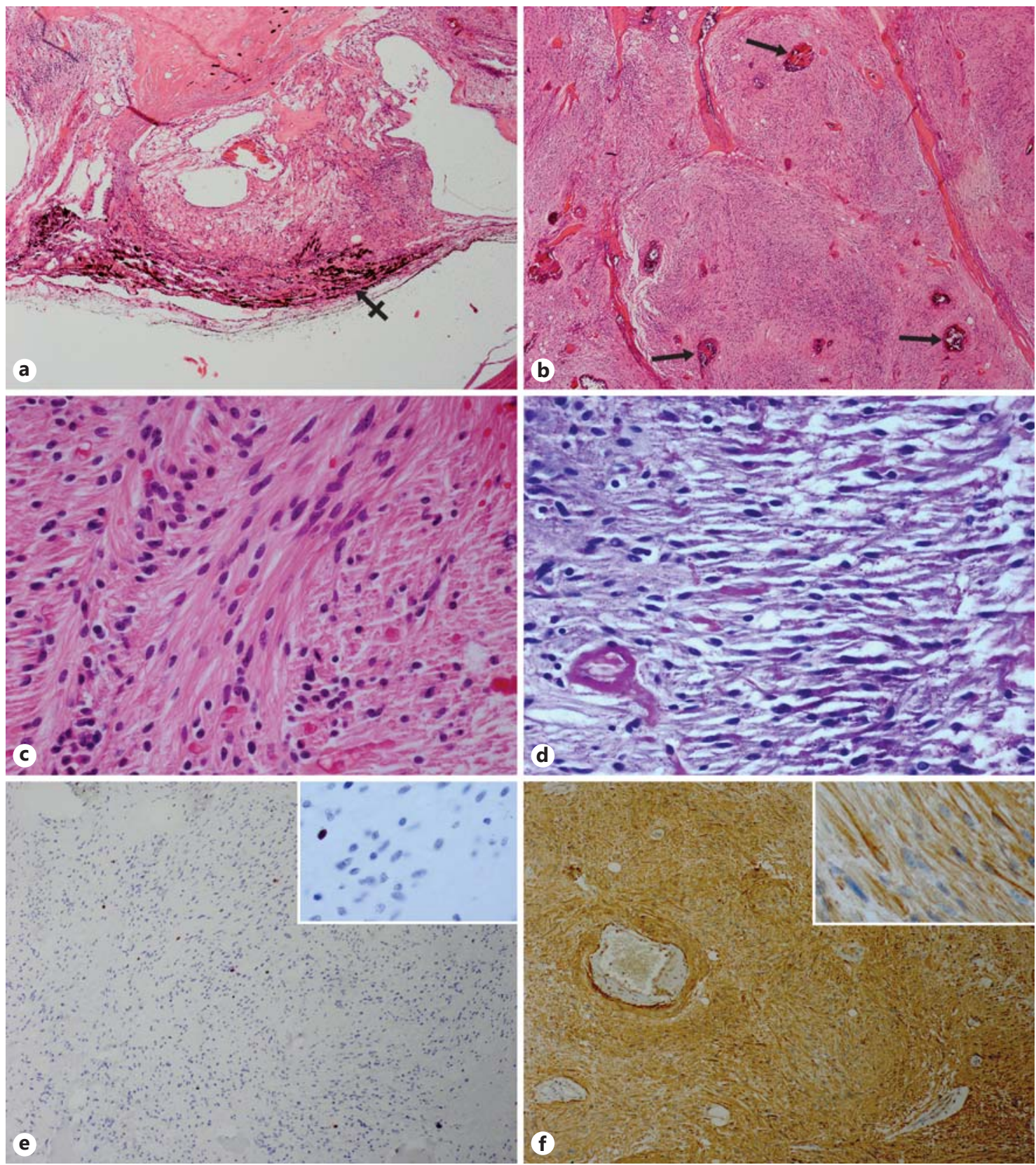

Fig. 4. Histology showed hyperplasia and fibrous metaplasia of the retinal pigment epithelium (crossed arrow) (a), scattered hyalinized vascular channels (arrows) (b), and spindle-shaped tumor cells with bland nuclei and filamentous eosinophilic cytoplasm (c, d). e Fewer than $5 \%$ of cell nuclei were Ki-67-positive. f Diffuse
GFAP immunostaining showed elongated fibrous astrocytes. a Hematoxylin and eosin, $\times 10$. b Hematoxylin and eosin, $\times 25$. c Hematoxylin and eosin, $\times 100$. d Periodic acid-Schiff, $\times 100$. e Ki-67, $\times 25$ (inset $\times 100)$. f GFAP, $\times 25$ (inset $\times 100$ ).
[10], 'neovascular fundus abnormalities' in uveitis [11], 'peripheral nodular retinal telangiectasis' [12], and 'angioma-like lesion in sickle cell disease' [13] were all subsequently used to refer to these cases. Shields et al. further characterized this entity clinically in a 12-patient series as

Reactive Retinal Astrocytic Tumor (Focal Nodular Gliosis) 'presumed acquired retinal hemangioma' [14] and later as 'vasoproliferative tumor' [6].

Each of the above terms emphasized vasogenesis as the mechanism driving disease. However, more recent histopathological analyses showed a predominant glial com- 
ponent to these tumors, with only minor presence of vasculature [1, 4, 5, 15-17]. A case series by Poole Perry et al. showed that even small, early-stage lesions with no prior treatment were predominantly gliotic rather than vascular, suggesting that vasoproliferation is a secondary or associated phenomenon in these tumors [3,4]. This group proposed 'reactive retinal astrocytic tumor' as a more appropriate term to emphasize the glial component of this entity [4]. The term 'focal nodular gliosis' has also been proposed for early stages of these tumors [1], while massive retinal gliosis probably represents the advanced stage of RRAT $[4,18,19]$. Recent gene expression profiling revealed that the most significantly upregulated genes in these masses were expressed by reactive astrocytes, while genes associated with Müller cells or angiogenesis were not differentially expressed [1], supporting characterization of this lesion as astrocytic in nature [3].

Microscopically, these tumors are predominantly composed of pilocytic (hairlike) fibrous astrocytes [1]. These elongated oval or spindle-shaped cells contain varying amounts of fibrillated eosinophilic cytoplasm and show diffuse immunopositivity for GFAP $[1,5,20$ 23]. Previous electron microscopy studies demonstrated features consistent with astrocytes, with absence of the abundant smooth and rough endoplasmic reticulum and interdigitating villous processes characteristic of Müller cells $[4,24]$. Rosenthal fibers and eosinophilic granular bodies can also be observed, and negative Alcian blue staining indicates absence of a myxoid acid mucopolysac- charide matrix [1]. Cells in these masses are mitotically quiet, with bland nuclei and low Ki-67 proliferative indices. Lesions are negative for the BRAF-KIAA gene rearrangement and IDH1-R132H mutation known to be associated with central nervous system astrocytomas [4, 25], further supporting the conclusion that these retinal tumors are not astrocytic neoplasms but rather reactive glial proliferations. Scattered, sclerotic vessels with hyalinized walls stain positive with periodic acid-Schiff. Progressive fibrous and osseous metaplasia of the retinal pigment epithelium eventually forms an outer rim of eggshell calcification [1].

The case described herein illustrates an example of progression of an RRAT to a massive retinal gliosis. The histological features are consistent with characterization as a reactive retinal gliosis and provide further evidence that the vascular component of these masses is minimal.

\section{Statement of Ethics}

This case report was granted exempt status by our Institutional Review Board.

\section{Disclosure Statement}

The authors have no financial or other conflict of interest in anything in this paper.

\section{References}

1 Jakobiec FA, Thanos A, Stagner AM, Grossniklaus HE, Proia AD: So-called massive retinal gliosis: a critical review and reappraisal. Surv Ophthalmol 2016;61:339-356.

2 Shields JA, Shields CL: Comment on: Reactive retinal astrocytic tumors (so-called vasoproliferative tumors): histopathologic, immunohistochemical, and genetic studies of four cases. Am J Ophthalmol 2013;156:202-203.

3 Jakobiec FA, Grossniklaus HE: Reply: To PMID 23219067. Am J Ophthalmol 2013;156: 203.

4 Poole Perry LJ, Jakobiec FA, Zakka FR, Reichel E, Herwig MC, Perry A, Brat DJ, Grossniklaus HE: Reactive retinal astrocytic tumors (so-called vasoproliferative tumors): histopathologic, immunohistochemical, and genetic studies of four cases. Am J Ophthalmol 2013;155:593-608.e1.
5 Shehri M, Bouhenni R, Ghazi NG, Abu Safieh L, Edward DP: Retinal reactive astrocytic tumor: gene expression profiling. JAMA Ophthalmol 2014;132:773-775.

6 Shields CL, Shields JA, Barrett J, Potter PD: Vasoproliferative tumors of the ocular fundus. Arch Ophthalmol 1995;113:615-623.

7 Henkind P, Morgan G: Peripheral retinal angioma with exudative retinopathy in adults (coats's lesion). Br J Ophthalmol 1966;50:211.

8 Welch R: Discussion: Presumed acquired retinal hemangiomas. Ophthalmology 1983;90: 1300.

9 Barr C, Rice T, Michels R: Angioma-like mass in a patient with retrolental fibroplasia. Am J Ophthalmol 1980;89:647-650.

10 Gottlieb F, Fammartino J, Stratford T, Brockhurst R: Retinal angiomatous mass. A complication of retinal detachment surgery. Retina 1984;4:152-157.
11 Felder K, Brockhurst R: Neovascular fundus abnormalities in peripheral uveitis. Arch Ophthalmol 1982;100:750-754.

12 Baines P, Hiscott P, McLeod D: Posterior non-vascularized proliferative extraretinopathy and peripheral nodular retinal telangiectasis. Trans Ophthalmol Soc UK 1982;102(Pt 4):487-491

13 Galinos S, Smith T, Brockhurst R: Angiomalike lesion in hemoglobin sickle cell disease. Ann Ophthalmol 1979;11:1549-1552.

14 Shields J, Decker W, Sanborn G, Augsburger J, Goldberg R: Presumed acquired retinal hemangiomas. Ophthalmology 1983;90: 1292-1300.

15 Smeets M, Mooy C, Baarsma G, Mertens D, Van Meurs J: Histopathology of a vasoproliferative tumor of the ocular fundus. Retina 1998;18:470-472. 
16 Irvine F, O’Donnell N, Kemp E, Lee W: Retinal vasoproliferative tumors: surgical management and histological findings. Arch Ophthalmol 2000;118:563-569.

17 Heimann H, Bornfeld N, Vij O, Coupland SE, Bechrakis NE, Kellner U, Foerster MH: Vasoproliferative tumours of the retina. $\mathrm{Br} \mathrm{J} \mathrm{Oph}$ thalmol 2000;84:1162-1169.

18 Yanoff M, Zimmerman LE, Davis RL: Massive gliosis of the retina. Int Ophthalmol Clin 1971;11:211-229.

19 Houston SK, Bourne TD, Lopes MB, Ghazi NG: Bilateral massive retinal gliosis associated with retinopathy of prematurity. Arch Pathol Lab Med 2009;133:1242-1245.
20 Jakobiec FA, Rashid A, Lewis K: Massive retinal gliosis in neurofibromatosis type 1. JAMA Ophthalmol 2015;133:100-102.

21 Inayama $\mathrm{Y}$, Hanashi M, Yazawa T, Mitsui $\mathrm{H}$, Kimura A, Ito D: Massive gliosis of the retina: report of a case investigated by immunohistochemistry and clonality assays. Hum Pathol 2005;36:702-705

22 Gelisken F, Inhoffen W, Rohrbach JM, BartzSchmidt KU: Massive retinal gliosis: a late complication of retinal detachment surgery. Graefes Arch Clin Exp Ophthalmol 2004;242: 255-258.

23 Deshmukh SD, Ashturkar AV, Babanagare SV, Gokhale SK, Deshpande AA: Massive retinal gliosis: an unusual case with immunohistochemical study. Indian J Ophthalmol 2011; 59:246-248.
24 Jakobiec F, Brodie S, Haik B, Iwamoto T: Giant cell astrocytoma of the retina. A tumor of possible Mueller cell origin. Ophthalmology 1983;90:1565-1576.

25 Schindler G, Capper D, Meyer J, Janzarik W, Omran H, Herold-Mende C, Schmieder K, Wesseling P, Mawrin C, Hasselblatt M, Louis DN, Korshunov A, Pfister S, Hartmann C, Paulus W, Reifenberger G, Von Deimling A: Analysis of BRAF V600E mutation in 1,320 nervous system tumors reveals high mutation frequencies in pleomorphic xanthoastrocytoma, ganglioglioma and extra-cerebellar pilocytic astrocytoma. Acta Neuropathol 2011; 121:397-405. 